\title{
A AUTOCOMPOSIÇÃO EM MATÉRIA TRIBUTÁRIA
}

\author{
The autocomposition in tax matters
}

\section{Leny do Nascimento Gomes}

Acadêmica do $10^{\circ}$ semestre do curso de Direito das Faculdades Integradas Machado de Assis - FEMA/ Santa Rosa/RS. Especialista em Gestão de Pessoas pela Faculdade da Amazônia - FAAM, Ananindeua/ Pará-Brasil. Possui graduação em Administração pela mesma Faculdade.

\section{Tiago Neu Jardim}

Mestre em Direito, com distinção, pela Universidade de Passo Fundo - UPF. Especialista em Finanças pelo Centro Universitário Franciscano - UNIFRA. Possui graduação em Ciências Econômicas pela Universidade Federal de Santa Maria - UFSM e em Direito pela mesma Universidade. Professor dos cursos de Ciências Econômicas da Faculdade Horizontina - FAHOR e de Direito das Faculdades Integradas Machado de Assis - FEMA/ Santa Rosa e da Sociedade Educacional Três de Maio - SETREM. É Procurador do Município de Horizontina/RS.

\section{Resumo}

O presente artigo versa sobre a possibilidade de extinção dos créditos tributários mediante concessões mutuas, ou seja, da aplicabilidade da resolução de conflitos em matéria tributária através da autocomposição. O problema da pesquisa reside na seguinte questão: os métodos alternativos de resolução de conflitos podem ser aplicados em matéria tributária sem que isso comprometa ou ponha em risco a indisponibilidade e a supremacia do interesse público? Para dar conta de responder a essa pergunta, foi preciso buscar as raízes do Sistema Tributário Brasileiro, procurando compreender o tributo a partir dos seus aspectos principiológicos. O propósito aqui foi o de tentar relativizar a tese da indisponibilidade, ainda muito arraigada ao Direito Administrativo, procurando demonstrar um novo conceito de interesse público, à luz da economicidade e da eficiência. Assim sendo, o objetivo geral do trabalho reside em avaliar os mecanismos extrajudiciais de solução de conflitos e seus benefícios a fim de propor a regulamentação e normatização de tais mecanismos no Sistema Tributário brasileiro. A pesquisa tem como justificativa a ineficiência dos métodos tradicionais de cobrança dos créditos tributários, dentre os quais a Execução Fiscal, que oneram demasiadamente os cofres públicos, além de ser moroso e pouco eficaz no que concerne à constrição do devedor que não possui patrimônio para saldar a dívida. A falta de autonomia da Fazenda Pública em extinguir o crédito tributário, em condições adversas como essa, expõe a precaridade do sistema de cobrança. A relevância da pesquisa reside, portanto, justamente em tentar propor um "novo" modelo arrecadatório, incorporando a hipótese de que dispor do crédito público em determinadas condições para tentar solucionar o conflito também é uma forma de atender ao interesse público.

Palavras-chave: Tributo. Arrecadação. Interesse público. Indisponibilidade. Autocomposição. Eficiência.

\section{Abstract}

This article deals with the possibility of extinguishing tax credits through mutual concessions, that is, the applicability of conflict resolution in tax matters through self - determination. The research problem lies in the following question: can alternative dispute resolution methods be applied in tax matters without compromising or jeopardizing the unavailability and supremacy of the public interest? In order to answer this question, it was necessary to seek the roots of the Brazilian Tax System, seeking to understand the tribute from its principiological aspects. The purpose here was to try to relativize the 
thesis of unavailability, still very much rooted in Administrative Law, trying to demonstrate a new concept of public interest, in the light of economy and efficiency. Thus, the general objective of the work is to evaluate the extrajudicial mechanisms of conflict resolution and its benefits in order to propose the regulation and regulation of such mechanisms in the Brazilian Tax System. The research has as justification the inefficiency of the traditional methods of collecting the tax credits, among which the Fiscal Execution, which overburden the public coffers, besides being slow and ineffective with regard to the constriction of the debtor who does not have assets to pay the debt. The lack of autonomy of the Public Treasury to extinguish the tax credit, under adverse conditions such as this, exposes the precariousness of the collection system. The relevance of the research is, therefore, precisely to try to propose a "new" collection model, incorporating the hypothesis that having public credit under certain conditions to try to solve the conflict is also a way to serve the public interest.

Keywords: Tribute. Collection. Public interest. Unavailability. Self-composition. Efficiency.

\section{Sumário}

1. Introdução; 2. Aspectos históricos da tributação e as raízes do sistema tributário brasileiro; 3. O interesse público e o paradigma da indisponibilidade; 4. Métodos alternativos de solução de conflitos; 5 . A autocomposição: espécies e principais benefícios materiais e processuais; 6 . Da execução fiscal a uma nova perspectiva do processo tributário; 7 . Considerações finais; 8. Notas; Referências

\section{INTRODUÇÃO}

O presente artigo encontra justificativa na falta de autonomia que tem a Fazenda Pública em celebrar a autocomposição no recebimento dos créditos tributários, visto que, de acordo com princípio da indisponibilidade do interesse público, à Administração Pública não cabe dispor do crédito tributário. A restrição do uso desses métodos alternativos de resolução de conflitos, devido em grande parte, a uma intromissão inadequada de alguns princípios administrativos no Direito Tributário, vem ocasionando aumentos significativos das demandas no Poder Judiciário brasileiro, onerando demasiadamente os cofres públicos, e elastecendo sobremaneira o tempo de cobrança e de recuperação do crédito público. A análise perpassa, ainda, pela necessidade de rever o paradigma da indisponibilidade e de redimensionar o conceito de interesse público.

Os métodos tradicionalmente utilizados na cobrança do crédito tributário, encontram-se ultrapassados, não suprindo os anseios da sociedade quando os recursos deixam de ser direcionados para o bem-estar do povo, e nem mesmo da Administração Pública que deixa de arrecadar, a cada ano, vultosas quantias devido ao exaurimento dos meios tradicionais de cobrança. Tomando por base o que revelam as pesquisas, o presente artigo versará sobre a possibilidade de extinção do crédito tributário mediante concessões mútuas, visto que, extinguir o crédito tributário, em condições adversas como essa, expõe a precariedade do sistema de cobrança.

A relevância da pesquisa reside, portanto, justamente em tentar propor um "novo" modelo arrecadatório, incorporando a hipótese de que dispor do crédito público em determinadas condições para tentar solucionar o conflito também é uma forma de atender ao interesse público. O problema da pesquisa reside, portanto, em responder à seguinte questão: os métodos alternativos de resolução de conflitos podem ser aplicados em matéria tributária sem que isso comprometa ou ponha em risco a indisponibilidade e a supremacia do interesse público?

Nesse sentido, o propósito deste artigo foi o de tentar relativizar a tese da indisponibilidade, ainda muito arraigada ao Direito Administrativo, procurando demonstrar um novo 
conceito de interesse público, à luz da economicidade, da eficiência e, acima de tudo, da eficácia arrecadatória. O objetivo geral do trabalho reside em avaliar os métodos extrajudiciais de solução de conflitos e seus benefícios para a sociedade diante da utilização de tais mecanismos no Sistema Tributário brasileiro como forma de agilizar o recebimento do crédito tributário por meio de ações mais céleres e menos dispendiosas para o erário. Os objetivos específicos se encontram consubstanciados em apresentar os mecanismos extrajudiciais de solução de conflitos atualmente existentes no Brasil e em analisar a real aplicabilidade do interesse público sobre o interesse privado bem como as eventuais restrições à transação em matéria tributária. Na metodologia utilizada, adotou-se a pesquisa teórica, pois sua temática foi desenvolvida por meio de documentação indireta (pesquisa documental e bibliográficas em livros, artigos científicos, doutrinas, legislações jurisprudenciais) e direta intensiva, consistindo em examinar fatos e fenômenos estatísticos.

No que concerne à produção dos dados, constitui-se em uma pesquisa quantitativa e qualitativa. Em relação à análise dos dados obtidos, foi utilizado o método de abordagem hipotético-dedutivo. Por fim, a hipótese sustentada é a de que se é possível ao Ente público dispor da totalidade do crédito tributário mediante remissão, então também deveria ser possível o recebimento de uma parcela do crédito nos casos em que existe reduzida ou nenhuma probabilidade de êxito na cobrança através de métodos forçados de execução, possibilitando a extinção do crédito mediante autocomposição. Para isso será preciso construir um novo paradigma de interesse público que leve em conta não apenas a expectativa de receita, mas acima de tudo os custos dessa improvável arrecadação. É preciso, pois, repensar o atual sistema de cobrança, incorporando a esse modelo uma perspectiva utilitarista e econômica, segundo a qual algumas vezes deixar de onerar os cofres públicos com instrumentos inadequados e pouco efetivos de arrecadação também é uma forma de atender ao interesse público.

\section{ASPECTOS HISTÓRICOS DA TRIBUTAÇÃO E AS RAÍZES DO SISTEMA TRIBUTÁRIO BRASILEIRO}

O Direito Tributário enquanto ramo cientificamente autônomo é relativamente recente. Durante muito tempo a tributação esteve atrelada à ciência das finanças ou ao orçamento público, estando, por isso, muito próximo da administração e da arte de governar. O Direito Tributário decorreu do Financeiro e ambos nasceram da necessidade de receita para o Estado como forma de suprir seu papel.

Nesse sentido, o Direito Tributário cuida apenas de parte da receita pública, ou seja, das entradas nos cofres do Estado que é o tributo e o Direito Financeiro tem por objetivo qualquer receita do Estado, seja ela proveniente de seu patrimônio, dos contribuintes, seja das próprias despesas. O Direito Financeiro regula toda a atividade financeira do Estado e não apenas os tributos enquanto que o Direito Tributário estuda apenas a receita compulsória e derivada que é o tributo. Mas nem sempre foi assim. A partir do século XVIII, a Europa sofre significativas mudanças em seu sistema de produção, visto que a situação econômica de Portugal passa por momento desfavorável economicamente não propiciando investimentos em caras e custosas viagens na busca de produtos a serem enviados à Europa por preços insignificantes e assim conclui pela ocupação das terras brasileiras e como atividade 
econômica passa a extrair pau-brasil árvore nativa brasileira.

A partir da ocupação, o Brasil passa a ser colônia de Portugal. Os primeiros anos de ocupação que se segue, Portugal procurou viabilizar o processo de ocupação do território brasileiro trabalhou na busca de criar condições para desenvolver atividades econômicas e rentáveis para tanto adotou os padrões administrativos da metrópole portuguesa. Nesse ínterim, imperava as leis fiscais desse país, como preleciona Martins,

\begin{abstract}
Portugal entendia que o pau-brasil era monopólio real. O particular, mediante contrato com a Coroa Portuguesa, poderia explorá-lo, mas deveria pagar um quinto do produto da venda. O pagamento era feito em espécie e não em moeda. Havia a cobrança de $10 \%$ sobre as mercadorias importadas e exportadas. Quinto era a quinta parte cobrada dos metais e pedras preciosas, como o ouro, prata etc. Dízimo era a cobrança da décima parte do pescado e das colheitas de todos os produtos da terra. Sisa era a cobrança por cabeça de índio tornado escravo (MARTINS, 2005, p. 22)
\end{abstract}

O autor faz referência a diversos impostos dentre os quais o "quinto", o qual decorria da cobrança do pau-brasil, tendo sido esse o primeiro tributo brasileiro exigido pela coroa portuguesa visto que à época era adotado os padrões administrativos da metrópole portuguesa. O Brasil sofre os impactos sobre os impostos cobrados por este país. As medidas relatadas permanecem até sua a independência. Os movimentos de independência, deu origem a elaboração da primeira Carta constitucional de 1824. Nesse período, o sistema de arrecadação era caótico, os tributos eram cobrados de maneira cumulativa, não havia no Brasil nada que pudesse ser caracterizado como sistema tributário, o que havia, era tão somente normas esparsas e sem qualquer conexão entre elas que pudessem ser caracterizadas como normas no sentido que entendemos hoje.

A Constituição de 1824, denominada Constituição do Império, apesar de pouco acrescentar em termos tributários elenca o princípio da capacidade contributiva na intenção de limitar o poder do Estado o qual expressa claramente em seu art. 179, inciso XV, "[...] ninguém será exempto de contribuir pera as despesas do Estado em proporção dos seus haveres" (BRASIL, 1824), e no item $X$ do art. 15 dispõe a competência do Poder Legislativo que fixa anualmente, as despesas públicas e a repartição a contribuição direta.

A regulamentação do Direito Tributário como ramo autônomo na ordem jurídica no Brasil, somente teve início a partir da Revolução Industrial com a Emenda Constitucional n 18 de 01 de dezembro do ano de 1965. Como bem adverte Nogueira (1995, p. 31), "[...] foi especialmente depois da I Guerra Mundial que o Direito Tributário veio alcançar a situação de ramo jurídico autônomo, pelo conteúdo e pela forma que hoje indiscutivelmente possui [...]". A nova norma instituiu uma classificação de impostos baseada em nomenclatura econômica e não mais jurídica, como ocorria antes.

Nessa vertente, a Constituição Federal de 05.10.1988, conservou no seu Capítulo I, Título VI, os artigos 145 a 162, que regulamenta o Sistema Tributário Nacional e estabelece os princípios gerais e as limitações ao poder de tributar, discriminando os impostos federais, estaduais e municipais e dispondo ainda sobre a repartição das receitas tributárias. O reconhecimento do Direito Tributário como o ramo autônomo, encontra-se elencado no Código Tributário Nacional - CTN e dispõem em seu Livro I sobre o Sistema Tributário Nacional e no Livro II sobre as Normas Gerais de Direito Tributário. Sendo classificado como ramo jurídico 
pertencente ao direito público.

A partir da autonomia do direito tributário, ocorre a evolução do Estado de Direito, a cobrança do tributo passa a ser disciplinada por força da lei conforme destaca Nogueira:

A tributação ou forma de obtenção da receita tributária foi assim, aos poucos, sendo disciplinadas por normas, paralelamente à evolução do constitucionalismo e influindo sobremodo no advento do Estado de Direito, hoje já alcançando a posição de Estado Social de Direito, no sentido de proteger, com mais intensidade, não apenas os direitos individuais, mas igualmente, os sociais [...] (NOGUEIRA, 1995, p. 5).

Com autonomia do direito tributário ocorre a evolução do Estado de Direito e a cobrança do tributo passa a ser exigida por força da lei. Dessa forma, pode-se assegurar que o Estado Moderno brasileiro se encontra amparado na lei, lei esta, que é votada em duas casas do Congresso Nacional. Para alguns autores há um questionamento quanto a autonomia do direito tributário, Sabbag adverte que a autonomia do Direito Tributário está longe de ser totalmente independente em relação aos demais ramos da ciência jurídica como segue:

[...] com boa dose de segurança, que o conhecimento do Direito Tributário está longe de prescindir do estudo das demais regras do ordenamento jurídico, afetas às ciências jurídicas, pois o direito tributário está visceralmente ligado a todo o universo das regras jurídicas em vigor, não podendo dispensar, nas suas construções, qualquer delas, por mais distante que possa parecer (SABBAG, 2015, p. 47).

De certa forma, constata-se que o Direito Tributário necessariamente se encontra entrelaçado aos demais ramos do direito, tais como o direito constitucional, o direito financeiro, o direito administrativo, o direito penal, o direito processual, o direito internacional público, o direito civil e outros ramos da ciência.

Nesse viés, Martins (2005, p. 36), adverte sobre a autonomia do direito no sentido de que ocorre apenas em aspecto puramente didático pois como segue: "[...] não se pode dizer, porém, que um ramo do Direito seria autônomo do próprio Direito, pois seria o mesmo que admitir a autonomia da espécie em relação ao gênero [...]", e acrescenta que somente haveria autonomia de um dos ramos do Direito se seus princípios, regras e instituições estabelecerem diferenças entre as demais searas e esclarece a possibilidade de duas teorias como segue:

\footnotetext{
A primeira teoria é denominada de monista. Ela entende que o Direito Tributário pertence ao Direito Financeiro e dele não se separou. A segunda teoria é chamada de dualista, indicando que o Direito Tributário é autônomo em relação ao Direito Financeiro. Tanto o Direito Financeiro, como o Direito Tributário são originários da mesma raiz, da necessidade de receita para o Estado poder cumprir seu papel. O Direito Tributário cuida apenas de parte das entradas nos cofres do Estado, apenas de parte da receita pública, que é o tributo. O Direito Financeiro tem por objetivo qualquer receita do Estado, seja ela proveniente de seu patrimônio, dos contribuintes, seja das próprias despesas. O Direito Financeiro regula toda a atividade financeira do Estado e não apenas os tributos. O Direito Tributário estuda apenas a receita compulsória e derivada que é o tributo. Não tem por objetivo estudar despesas públicas, que ficam a cargo do Direito Financeiro (MARTINS, 2005, p. 36)
}

O autor assinala que para o Direito Tributário ser autônomo, necessariamente deveria existir um método próprio no estudo do direito, o que não ocorre. Pois para o autor, "[...] o método é um só e vale para todos os seus ramos" (MARTINS, 2005, p. 36). Para melhor esclarecer a autonomia do direito o Art. 109 do CTN, estabelece a autonomia do Direito 
Tributário com relação a outros ramos do Direito por conter princípios próprios como o da legalidade tributária, capacidade contributiva, anterioridade, proibição do confisco dentre outros. Tem autonomia didática, pois as faculdades de Direito oferecem cadeira própria, ou seja, oferecem no mínimo dois semestres da disciplina. As faculdades Ciência Econômica, Ciências contábeis e administração oferecem uma cadeira.

Os Princípios Constitucionais regedores da Administração Pública encontram-se elencados no caput do art. 37 da Constituição Federal de 1988. Tais princípios nem sempre se encontram de forma explicita. Para a doutrina e a jurisprudência independentemente de estarem ou não explícitos, os princípios possuem a mesma relevância jurídica. O teor do art. $4^{\circ}$ da lei 8.429/92 (Lei de improbidade administrativa), com clareza define: "Os agentes públicos de qualquer nível ou hierarquia são obrigados a velar pela estrita observância dos princípios de legalidade, impessoalidade, moralidade e publicidade no trato dos assuntos que lhes são afetos" (BRASIL, 1992).

Nesse sentido, o Direito Tributário está informado por princípios próprios. Esses princípios permitem que a Administração e o Judiciário estabeleçam o necessário equilíbrio entre os direitos dos administrados e as prerrogativas do administrador. Celso Antônio Bandeira de Mello ao dispor sobre os princípios tributários afirma que:

\footnotetext{
Princípio é por definição, mandamento nuclear de um sistema, verdadeiro alicerce dele, disposição fundamental que se irradia sobre diferentes normas. Compondo- Ihes o espírito e servindo de critério para a sua exata compreensão e inteligência exatamente por definir a lógica e a racionalidade do sistema normativo, no que Ihe confere a tônica e lhe dá sentido harmônico (MELLO, 2002, apud ALEXANDRE, 2013, p. 116).
}

Nesse diapasão, pode-se afirmar que somente a partir de um estudo minucioso dos princípios, é que se poderá compreender as normas integrantes de um determinado ramo do direito como um todo no ordenamento jurídico. Os Princípios da Administração Pública (direta e indireta), encontram previsão Constitucional expressa em rol exemplificativos no art. 37, caput da Constituição Federal de 1988, e contempla os princípios regentes da Administração Pública, dispondo sobre a legalidade, da impessoalidade, da moralidade, da publicidade e da eficiência, este último acrescentado pela EC 19/98. No Título VI, (Da tributação e do Orçamento), Capítulo I (Do sistema tributário nacional), arts. 145 a 162.

Os princípios tributários decorrem do texto constitucional e tem por objetivo estabelecer regras gerais de tributação, encontram-se elencados na Lei $n^{\circ} 5.172 / 66$, CTN, sendo esta lei, considerada uma Lei Complementar. Nesse entendimento Nogueira, assinala que,

Os princípios constitucionais que incidem diretamente sobre o campo tributário
são mesmo princípios constitucionais tributários, comando da tributação, mas
além desses, há princípios constitucionais não tributários e que estão relacio-
nados, por suas consequências, com o Direito Tributário. Assim, por exemplo,
o princípio constitucional que garante o exercício de profissão lícita ou da livre
iniciativa. O poder tributário não poderá impedir essa garantia, antes deverá ser
exercido em harmonia com esse princípio. Outro exemplo é a garantia consti-
tucional da propriedade; por isso um tributo não pode ter efeito confiscatório,
daí se vê que são precisas as vinculações entre esses dois ramos jurídicos,
pois a própria lei tributária não terá valor, se for inconstitucional (NOGUEIRA,
1995, p. 68)

Isto posto pode-se afirmar que os princípios são construções que servem de base 
ao Direito como fontes de sua criação, aplicação ou interpretação. Sua finalidade é nortear a cobrança dos impostos e a sistematização da realização da atividade estatal, de forma a assegurar o cumprimento dos fins a que se dispõe. Nessa vertente, Machado (2015, p. 44), afirma que "[...] os princípios jurídicos da tributação existem para proteger o cidadão contra os abusos do poder".

Os princípios tributários na verdade, são considerados como limitações constitucionais ao poder de tributar e por definição legal é prestação "instituída em lei" como dispõe o artigo $3^{\circ}$ do CTN (BRASIL, 1966). A Lei 9.784, de 29.1.1999, regula o processo administrativo no âmbito da Administração Pública Federal, em art. $2^{\circ}$, relaciona como princípios, a legalidade, a finalidade, a motivação, a razoabilidade, a proporcionalidade, a moralidade, a ampla defesa, o contraditório, a segurança jurídica, o interesse público e a eficiência. A partir do estudo e análise dos princípios compreende-se que o Direito Tributário tem princípios próprios, instituições próprias, conceitos e regras próprias o que enseja a sua autonomia pelo simples fato de existir um Código de forma sistemática e ordenada.

O princípio da legalidade é um princípio basilar da Administração Pública, e encontra previsão constitucional no caput do art. 37 e art. 150, inciso I da Constituição Federal e no plano infraconstitucional, no art. 97 da lei n 5.172/66 (Código Tributário Nacional), tendo carga valorativa. A legalidade tributária comporta um dos princípios basilares da tributação visto que a natureza do Direito Tributário, portanto é ex lege, ou seja, decorre da previsão da lei. A esse respeito Sabbag dispõe sobre o Princípio da Legalidade na orbita doméstica:

\footnotetext{
O princípio da legalidade é multissecular, com previsão na Carta Magna inglesa, de 1215, do Rei João Sem Terra. À época, a nobreza e a plebe, reunindo esforços e se insurgindo contra o poder unipessoal de tributar, impuseram ao príncipe João um estatuto, visando inibir a atividade tributária esmagadora do governo. Em outras palavras, objetivavam impor a necessidade de aprovação prévia dos súditos para a cobrança dos tributos [...] (SABBAG, 2015, p. 59-60).
}

Diante de tal afirmação, percebe-se que a legalidade sempre foi instrumento de desejado da população, mas a previsão legal somente se concretizou a partir de uma nova fase da tributação, fase essa denominada de "Estado de Direito". Onde não é mais permitido o cometimento de ações arbitrárias por particulares, ou seja, a exigência de cobrança de tributos sem critérios baseado tão somente na relação força/poder não é mais permitido. A lei passa a ser interpretada e aplicada pelo poder judiciário, tal como assinala Nogueira,

\footnotetext{
O tributo atingiu assim a situação atual de categoria jurídica e o obrigado status de cidadão- contribuinte. Aquele que é juridicamente obrigado o é nos termos e limites da lei. Não precisa fazer doações, prestar simples favores ou auxílios, nem ficar sujeito a surpresas, excessos ou confiscos, mas deverá compulsoriamente contribuir para os gastos públicos na proporção de seus haveres, na medida e na conformidade da lei (NOGUEIRA, 1995, p. 6).
}

A partir do Estado de Direito, o fenômeno da tributação passa a ser juridicizado e realizado dentro da legalidade. Os princípios jurídicos a partir de então, passam a orientar os entes tributantes assinalando que estes não poderão exigir ou aumentar tributos sem antes sejam estabelecidos por lei. A partir dessa nova definição, "[...] a lei é a proposição jurídica que trata igualmente todos que estejam na mesma situação. A vontade da lei se impõe tanto aos particulares como aos agentes do Estado e ao próprio Estado como pessoa de direitos e obrigações", como bem define Nogueira (1995, p. 6). A legalidade na Administração não 
se resume à ausência de oposição à lei, mas pressupõe autorização dela, como condição de sua ação. Desse modo, Hely Lopes Meirelles ensina que:

A legalidade, como princípio de administração (CF, art. 37caput), significa que o
administrador público está, em toda sua atividade funcional, sujeito aos manda-
mentos da lei e às exigências do bem comum, e deles não se pode afastar ou
desviar, sob pena de praticar ato inválido e expor-se a responsabilidade discipli-
nar, civil, criminal, conforme o caso (MEIRELLES, ALEIXO, FILHO, 2015, p. 90).

Isto posto, tal fundamento se firma nos ideais de segurança jurídica tal qual dispõe o artigo 97, inciso I do CTN, "Somente lei pode estabelecer a instituição de tributos, ou a sua extinção". A orientação é clara ao que tange os entes tributantes que não poderão exigir ou aumentar tributos sem que a lei anteriormente o prescreva, visto que a Constituição em seu art. $5^{\circ}$, II, estatui que "[...] ninguém será obrigado a fazer ou deixar de fazer alguma coisa senão em virtude de lei" (BRASIL, 1988), o que sinaliza que qualquer excesso em relação à lei constituirá um vício que pode ser submetido a controle jurisdicional, vício esse denominado ilegalidade.

Nesse diapasão, Costa (2012, p. 160), dispõe que o "[...] controle de legalidade é aquele que diz respeito à observância dos atos administrativos praticados com os dispositivos delineados na lei”. Mas é importante frisar que algumas matérias não estão sujeitas ao princípio da legalidade, podendo ser disciplinadas por meio de ato infra legal, como é o caso de Decreto Presidencial.

\section{O INTERESSE PÚBLICO E $O$ PARADIGMA DA INDISPONIBILIDADE}

O Princípio da Indisponibilidade do Interesse público é também denominado de princípio da supremacia do interesse ou da finalidade pública (MEIRELLES, ALEIXO, FILHO, 2015). Constitucionalmente, é um princípio implícito no qual os autores têm certa dificuldade em estabelecer uma nomenclatura exata. Para Meirelles (2015, p. 110), o fato de tal dificuldade, advém de que o "[...] interesse público prevalente é extraído da ordem jurídica em cada caso concreto". Vale destacar que os princípios da supremacia do interesse público sobre o interesse privado e o princípio da indisponibilidade de interesse público, são princípios fundamental do regime jurídico do direito público e é observância obrigatória pela Administração Pública, pois todo o Sistema de Direito Administrativo está subordinado a esses dois princípios.

O Princípio da Indisponibilidade do Interesse público sobre o interesse privado se torna evidente no art. $5^{\circ}$, incisos XXIV e XXV da Constituição Federal. Sua fundamentação encontra-se estabelecida em lei infraconstitucional especificamente no art. $2^{\circ}$ da Lei 9.784 de 29 de janeiro de 1999, lei esta, que regula o Processo Administrativo no âmbito da Administração Pública Federal direta e indireta. O art. $2^{\circ}$, Parágrafo Único, inciso II da referida lei, estabelece critérios a serem observados no Processo Administrativo, quais sejam: atendimento a fins de interesse geral, vedada a renúncia total ou parcial de poderes ou competências, salvo autorização em lei. Dessa forma, Mello entende que,

[...] o interesse público deve ser conceituado como o interesse resultante do conjunto dos interesses que os indivíduos pessoalmente têm quando considerado em sua qualidade de membros da Sociedade e pelo simples fato de o serem (MELLO, 2014, p. 62). 
Cumpre ressaltar que o interesse público representa o somatório dos interesses individuais que representa a vontade da maioria. O interesse público pode ser primário (vontade do povo) ou secundário (vontade do Estado enquanto pessoa jurídica) (MELLO, 2014). O ideal é que tais interesses sejam coincidentes, pois do contrário, prevalecerá o interesse primário, ocorrerá a interferência do Poder Judiciário. Nesse entendimento, Meirelles dispõe que do Princípio da Supremacia do Interesse Público,

\footnotetext{
[...] decorre o princípio da indisponibilidade do interesse público, segundo o qual a Administração Pública não pode dispor desse interesse geral, da coletividade, nem renunciar a poderes que a lei lhe deu para tal tutela, mesmo porque ela não é titular do interesse público, cujo titular é o Estado, como representante da coletividade, e, por isso, só ela, pelos seus representantes eleitos, mediante lei, poderá autorizar a disponibilidade ou a renúncia (MEIRELLES, ALEIXO, FILHO, 2015, p. 110).
}

As pessoas administrativas não têm disponibilidade sobre os interesses públicos confiados à sua guarda e realização. AAdministração Púbica não pode proceder com a mesma desenvoltura e liberdade com que agem os particulares, visto que ao particular é lícito fazer tudo que a lei não proíbe, enquanto que ao administrador público só é permitido agir de acordo com a lei. Nesse entendimento ocorre que à Administração Pública não cabe a renúncia (dispor) do interesse público, salvo quando autorizada pelo direito. Nesse sentido os poderes da Administração têm caráter de poder-dever, os quais ela não pode deixar de exercer sob pena de responsabilização por omissão. Assim sendo, a autoridade administrativa não pode renunciar ao exercício das competências que lhe são atribuídas por lei. O paradigma da indisponibilidade, importado do Direito Administrativo, restringe as possibilidades que a Fazenda Pública e os Procuradores têm de entabular acordos e fazer transações, ainda que disso decorra maior eficácia na cobrança e satisfatividade na Execução, reduzindo o tempo da cobrança e os custos incorridos na Execução Fiscal. Com efeito, se o Ente público pode fazer a remissão do seu crédito, desde que observados os limites impostos pela Lei de Responsabilidade Fiscal, por que não poderia dele dispor parcialmente para tentar evitar a frustração completa da arrecadação? Afinal, quem pode o mais, também deveria poder o menos. É nesse sentido que os métodos alternativos de solução de conflitos contribuem para trazer mais efetividade na cobrança da dívida ativa. Para isso, contudo, é preciso substituir a ideia de que, ao transacionar, o fisco estaria abrindo mão de um bem coletivo pela concepção racional e utilitarista de que, ao fazer isso, a Fazenda Pública ganha maior liquidez, melhora o seu fluxo de caixa e reduz despesas para a recuperação de créditos com poucas chances de satisfatividade.

\section{MÉTODOS ALTERNATIVOS DE SOLUÇÃO DE CONFLITO}

O conflito se fez presente na história da humanidade. A luta pelo poder ocorria por meio das batalhas armadas. Na história do Direito Tributário, não foi diferente, o conflito foi parte integrante, és que ainda nos dias de hoje as formas conflitantes se fazem presentes atingindo diretamente a sociedade em todas as esferas sociais. Ao que tange a cobrança do crédito tributário, o conflito persiste, de forma que figura como agente central na cobrança de créditos tributários entre o fisco e o contribuinte. Para esclarecer melhor Vasconcelos, sintetiza o "conflito" da seguinte maneira: 


\begin{abstract}
Embora seja contingencia da condição humana, e, portanto, algo natural numa disputa conflituosa costuma-se tratar a outra parte como adversária, infiel ou inimiga. Cada uma das partes da disputa tende a concentrar todo o raciocínio e elementos de prova na busca de novos fundamentos para reforçar a sua posição unilateral, na tentativa de enfraquecer ou destruir os argumentos da outra parte. Esse estado emocional estimula as polaridades e dificulta a percepção do interesse comum (VASCONCELOS, 2014, p. 21).
\end{abstract}

O autor alerta para a importância da conscientização do conflito por tratar-se de algo inerente às relações humanas e deixa evidente que o conflito, não deve ser encarado de forma negativa ao afirmar que, "[...] o conflito, quando bem conduzido, evita a violência e pode resultar em mudanças positivas e novas oportunidades de ganho mútuo" (VASCONCELOS, 2014, p. 21). Nesse diapasão, Vasconcelos (2014, p. 24) adiciona ainda que, "[...] ao se compreender a inevitabilidade do conflito se é capaz de desenvolver soluções autocompositivas". Seguindo o mesmo entendimento, Bastos; Corrêa; Passani, (2014, p. 69), afirmam que "[...] o conflito não é positivo nem negativo, nem destrutivo nem produtivo: é ambos de uma só vez. É o modo como enfrentamos que fará que tome um curso destrutivo ou positivo".

Dessa forma, pode-se concluir que o conflito pode tornar-se nocivo ou benéfico à sociedade, para tal, dependerá da importância que lhe será dado de forma que a solução do conflito dependerá da pessoa que o conduzirá. Em termos práticos, na história do Brasil, sempre existiu grande preocupação em se solucionar conflito de forma pacífica, é o que dispõe o Livro $3^{\circ}, \mathrm{T} 20, \S 1^{\circ}$ das Ordenações Filipinas conforme segue:

Livro $3^{\circ}, T 20, \S 1^{\circ}$ : E o começo da demanda dirá o juiz a ambas as partes que, antes que façam despesas e se sigam entre eles os ódios e dissensões, se devem concordar, e não gastar suas fazendas por seguirem suas vontades, porque o vencimento da causa sempre é duvidoso (BASTOS; CORREA; PASSANI, 2014, p. 20).

Tal ordenamento também pode ser percebido no art. 161 da Constituição do Império de 1824: "Art. 161: Sem se fazer constar que se tem intentado o meio de reconciliação, não se começará processo algum, e, sem se demonstrar que se tentou uma solução amigável, ninguém será admitido em juízo" (BRASIL, 1824).

Assim, as inovações introduzidas no ordenamento jurídico brasileiro, faz com que a sentença de mérito muitas vezes, põe fim apenas à lide no plano de direito, mas nem sempre extingue o conflito entre as partes, o que torna necessário a utilização de mecanismos de pacificação social capazes de regular a ação do homem, ou seja, pacificar as ações conflitantes de forma breve, objetiva e satisfatória.

Foi pensando em uma justiça célere que no ano 1982, foi criada a Associação dos Juízes do Estado do Rio Grande do Sul (AJURIS), por iniciativa do Magistrado Luiz Antônio Corte Real, tendo sido instalada na Comarca do Rio Grande, o Conselho de Conciliação e Arbitramento. De acordo Giacomolli, o Conselho era denominado, popularmente, de Juizado de Pequenas Causas,

Esse conselho tinha por objetivo aproximar o Poder Judiciário da população mais carente, a qual, via de regra desconhece, os meios que possui quando seu direito é atingido ou não dispõe de condições econômicas para reivindicar seus direitos, permanecendo sem acesso à prestação Jurisdicional (GIACOMOLLI, 2009, p. 13). 
O objetivo do Conselho como bem dispõe o autor, era aproximar a sociedade do poder judiciário, pois assim estabelece o Princípio do Acesso à Justiça (inciso XXXV do art. 5. ${ }^{\circ}$ ) da Constituição Federal de 1988, que assim estabelece: "a lei não excluirá da apreciação do Poder Judiciário lesão ou ameaça a direito" (BRASIL, 1988). O objetivo do Conselho foi almejado, tendo sido editada em 26.09.1995, a Lei n. 9.099 - Lei dos Juizados Especiais. De acordo com o art. $3^{\circ}, \S 2^{\circ}$ da referida lei, ficou de fora certas peculiaridades conforme segue:

\footnotetext{
Art. $3^{\circ}$ : O juizado Especial Cível tem competência para conciliação, processo e julgamento das causas cíveis de menor complexidade, assim consideradas:

$\S 2^{\circ}$ Ficam excluídas da competência dos Juizados Especiais as causas de natureza alimentar, falimentar, fiscal e de interesse da Fazenda Pública, e também das relativas a acidentes de trabalho, a resíduos e ao estado e capacidade das pessoas, ainda que de cunho patrimonial (BRASIL, 1995).
}

Em razão de tal dispositivo, as causas relativas à Fazenda Púbica ficaram excluídas da apreciação da Lei n. 9.099 de 1995 - a qual passa a dispor tão somente sobre as causas Cíveis e Criminais. O Princípio do Acesso à Justiça referido no inciso XXXV do art. $5 .^{\circ}$ da Constituição Federal de 1988, constitui para Bastos, Corrêa e Passani, uma interpretação restritiva:

[...] durante muito tempo esse acesso à justiça foi interpretado de forma restritiva: o acesso única e exclusivamente por meio dos processos judiciais. Mas a realidade brasileira atual torna imprescindível que essa interpretação inclua outras formas de socorrer os cidadãos de modo mais abrangentes [...] (BASTOS; CORRÊA; PASSANI, 2014, p. 19).

O autor sugere métodos alternativos de Resolução de Conflitos condizentes com a atual realidade da sociedade as quais inclui a mediação, a negociação, a conciliação, a arbitragem entre outros, pois os métodos assinalados, constituem estímulo às pessoas, tornando-as empoderadas para solucionar seu próprio conflito.

Seguindo esse entendimento, "Podemos dividir os meios de solução de conflito em três grandes grupos: autocomposição, heterocomposição e autotutela". (MOORE, 1998, apud BASTOS; CORREAA; PASSANI, 2014, p. 72). Os Métodos ou Meios Alternativos de Solução de Conflitos - MASCs, ou, Meios Extrajudiciais de Solução os Conflitos MESCs, apresentados pelo autor, seja judicial ou extrajudicial de acesso à justiça, compõe hoje o denominado sistema multiportas que engloba as práticas restaurativas, de facilitação de diálogos, entre outros. Meios dos quais o cidadão pode utilizar aquele que se mostre mais adequado em cada caso concreto de forma que possa constituir maior vantagem para a coletividade.

\section{A AUTOCOMPOSIÇÃO: ESPÉCIES E PRINCIPAIS BENEFÍCIOS MATERIAIS E PROCESSUAIS}

Em se tratando dos métodos autocompossitivos, pode-se afirmar que a autocomposição é um importante mecanismo de pacificação social, uma prática de solução pacífica da controvérsia pelos próprios interessados, que chegam a um resultado consensual sem a intervenção de terceiros. Dentro do processo de autocomposição encontram-se inseridas a negociação, a conciliação e a mediação as quais serão identificados no decorrer do estudo tal qual suas principais peculiaridades.

A negociação é uma forma de autocomposição direta onde as partes se unem volun- 
tariamente sem a interferência de um terceiro num relacionamento temporário. Esse método de resolução de conflitos advém da transação que é definida por Vasconcelos (2014, p. 54) como "[...] o planejamento, a execução e o monitoramento, sem a interferência de terceiros, envolvendo pessoas, problemas e processos na ou transformação ou restauração, na solução de disputas ou troca de interesses".

A negociação é um método que tem por finalidade a união das partes, ou seja, "informar a outra parte sobre suas necessidades e interesses, trocar informações específicas ou resolver questões" (BASTOS; CORRÊA; PASSANI, 2014, p. 72). Nesse encontro, as partes têm objetivos comuns e cada um ouve o outro despidos de interesses que não verse sobre a causa do litigio, o que se busca é um acordo de ganhos mútuos. Quando a negociação não alcança êxito (não é possível diretamente com a pessoa envolvida), para retomar o diálogo torna-se necessário a colaboração de uma terceira pessoa, que atuará como mediadora. Para bem esclarecer, os termos da negociação é confidencial.

A transação por sua vez encontra-se inserida dentro do contexto da autocomposição e encontra fundamento no artigo 98, inciso I e artigo 156, inciso III da Constituição Federal de 1988 e ainda na lei infraconstitucional art. 171caput do CTN. No CTN, a transação figura como sendo o instituto jurídico de natureza contratual que tem por objetivo, dentre outras finalidades, extinguir o crédito tributário. A transação só será permitida em relação a direitos patrimoniais. Para tanto a jurisprudência prevê a realização da transação mediante requisitos que possibilitem extinguir o credito tributário.

Os requisitos da transação, possibilita que as partes utilizem os métodos da negociação, da conciliação e da mediação. A conciliação é uma forma indireta de autocomposição adotada pelo CNJ desde de 2006 como forma extrajudicial de solução de conflitos. O CNJ há nove anos promove as Semanas Nacionais pela Conciliação, momento em que os tribunais são incentivados a juntar as partes e promover acordos pré-processual e endo processual. A conciliação pode ser definida como ato processual que só pode ocorrer na presença do magistrado onde a atividade mediadora é focada no acordo.

Por meio do mecanismo da conciliação, um terceiro neutro e imparcial, é escolhido pelas partes ou designado pelo tribunal para intermediar as discussões. O conciliador não pode dizer quais são os direitos das partes, mas somente orientá-las, exerce a função de um facilitador de diálogos. Vasconcelos, dispõe sobre a conciliação da seguinte forma:

\footnotetext{
[...] a conciliação é uma atividade mediadora focada no acordo, qual seja, tem por objetivo central a obtenção de um acordo, com a particularidade de que o conciliador exerce leve ascendência hierárquica, pois toma iniciativas, faz recomendações, advertências e apresenta sugestões com vistas à conciliação (VASCONCELOS, 2014, p. 58).
}

Nesse sentido, a conciliação é Ato Jurisdicional por meio do qual as partes litigantes sobre a interveniência da autoridade jurisdicional transacionam matéria objeto da lide. A conciliação encontra fundamento nos princípios da Independência, (pode ocorrer em qualquer momento do processo); da Imparcialidade (daquele que promover a conciliação); da Autonomia (da vontade das partes); da Confidencialidade e da Oralidade/Informalidade. No processo de conciliação, busca-se soluções que atendam aos interesses de todos (ganha-ganha). 
A Mediação trata-se de um método dialogal e auto compositivo, é um procedimento todo oral e desburocratizado que ocorre de forma voluntária entre as partes e está consubstanciada na Lei n. 13.140 de 26 de junho do ano de 2015. A referida lei, dispõe sobre a mediação como meio de solução de controvérsias entre particulares e sobre a autocomposição de conflitos no âmbito da Administração Pública. O parágrafo único do art. $1^{\circ}$ da lei em comento, estabelece a mediação como "[...] atividade técnica exercida por terceiro imparcial sem poder decisório que, escolhido ou aceito pelas partes, as auxilia e estimula a identificar ou desenvolver soluções consensuais para a controvérsia" (BRASIL, 2015). Ao mediador cabe tão somente colaborar com os mediandos, para que estes pratiquem uma comunicação construtiva e identifiquem seus interesses e necessidades comuns. Nessa perspectiva, Vasconcelos, esclarece os procedimentos para mediação conforme segue:

\begin{abstract}
[...] os mediandos escolhem ou aceitam terceiro(s) mediador(es), com aptidão para conduzir o processo e facilitar o diálogo, a começar pelas apresentações, explicações e compromissos iniciais, sequenciando com narrativas e escutas alternadas dos mediandos, recontextualizações e resumo do(s)mediador(es), com vistas a se construir a compreensão das vivencias afetivas e materiais da disputa, migrar das posições antagônicas para a identificação dos interesses e necessidades comuns e para o entendimento sobre as alternativas mais consistentes, de modo que, havendo consenso, seja concretizado o acordo. (VASCONCELOS, 2014, p. 54).
\end{abstract}

Vale esclarecer que a mediação possui até oito fases que são a pré-mediação, a abertura, a investigação do conflito, agenda organizada das prioridades, alternativas, escolha de opção e fechamento ou termo de acordo e compõe de sete técnicas: escuta ativa, parafraseamento (ato de repetir as respostas), formulação de perguntas que induzam à solução, resumo seguido de confirmações, isolamento, tempestade de ideias e teste de realidade. "O teste de realidade trata-se do dever de assegurar que os envolvidos, ao chegarem a um acordo, compreendam perfeitamente suas disposições, que devem ser exequíveis, gerando o comprometimento com seu cumprimento" (BRASIL, 2010). A título de esclarecimento, não há obrigatoriedade em seguir todos os tramites apresentados. As técnicas de mediação, tratam-se de alternativas multidisciplinares onde se faz necessário conhecimentos jurídicos, sociológicos, psicológicos, contábeis dentre outros. Segundo Bastos; Corrêa; Passani,

[...] a mediação pode tratar de todo o conflito ou apenas de parte dele e se divide em três tipos:

Extrajudicial: é feita antes do ingresso de um processo na Justiça. As partes em conflito buscam mediadores e, havendo um acordo, a decisão tomada terá força de uma sentença judicial, sendo a assistência por advogado obrigatória, a menos que as partes abram mão desse direito;

Judicial: quando há um processo no Judiciário. A mediação terá um prazo de 60 dias para acontecer e, somente não havendo acordo, o processo passará a tramitar normalmente no judiciário;

Pública: quando os conflitos envolvem a União, os Estados, Distrito Federal e os Municípios, a Administração Pública Federal direta, suas autarquias e fundações (BASTOS; CORRÊA; PASSANI, 2014, p. 26).

Dentre as formas de resolução de conflitos apresentadas, temos ainda o processo judicial que aborda o conflito como um fenômeno exclusivamente jurídico, ou seja, como lide processual. A lide processual pode excluir aspectos relevantes para as partes por não levar em consideração as emoções (lide social), visto que o conflito na relação processual pode se tornar mais gravoso para as partes. 


\title{
6. DA EXECUÇÃO FISCAL A UMA NOVA PERSPECTIVA DO PROCESSO TRIBUTÁRIO
}

A execução fiscal no Brasil é regida pela lei especial de $n^{\circ} 6.830$ de 22 de setembro do ano de 1980 e dispõe sobre a cobrança judicial da Dívida Ativa da Fazenda Pública, da União, dos Estados, do Distrito Federal, dos Municípios e respectivas autarquias, aplicando-se subsidiariamente, as disposições do Código de Processo Civil no que se refere à execução em geral. A lei de execução fiscal também é classificada como uma subespécie de execução por quantia certa, fundada em título executivo extrajudicial.

Nesse entendimento, tem-se que a Lei $6.830 / 80$ foi editada precipuamente objetivando conferir maior celeridade e eficiência à cobrança dos créditos tributários, uma vez que a Fazenda Pública tem a imperatividade na defensa do interesse público. De forma que o PL $5.282 / 2009$ traz novas possibilidades de resolução na cobrança do crédito tributário pela Fazenda Pública e a extinção do credito tributário, por meio de transação tributária. Sendo que para haver transação, deve-se existir um litígio visto que a transação só irá ocorrer depois da existência do litígio e não antes dele. Logo, não se aplica a regra do art. 840 do Código Civil no sentido de que a transação irá prevenir litígio. Todavia de acordo com o que dispõe Martins (2005, p.213), a transação só poderá ocorrer se houver previsão legal:

\begin{abstract}
A transação tributária tem como pressuposto a existência de lei regulando o assunto. Não havendo lei, a transação não pode ser feita. Assim a autoridade administrativa não está autorizada a transigir, salvo na existência de lei expressa nesse sentido. Do contrário, poderia haver malversação do dinheiro público, com compensação de dívidas por interesses pessoais de cada administrador (MARTINS, 2005, p. 213).
\end{abstract}

Nesse sentido, a palavra litígio empregada no art. 171 do CTN, somente é caracterizada com a instauração da lide, que quer dizer na pretensão formulada e resistida em juízo. Caso a lei determine a transação, esta poderá ser feita tanto no processo judicial quanto no processo administrativo, levando-se em consideração que o aumento do número de processos judiciais, representam custos elevados, tanto para as empresas quanto para o Estado durante os processos. De acordo com Bastos; Corrêa; Passani, pesquisas que retrata o custo das empresas para litigar judicialmente,

\footnotetext{
[...] demonstrou que o comprometimento das finanças das empresas com processos judiciais chega a quase $2 \%$ do que faturam em um ano, percentual que, em 2012, representou $R \$ 110,96$ bilhões. O levantamento partiu da análise das demonstrações financeiras de 7.485 empresas, de 21.647 processos judiciais, da arrecadação tributária de 2012, e do faturamento das empresas por CNAE do Instituto Brasileiro de Planejamento e Tributação (IBPT). Em 2012, existiam 74,38 milhões de ações na Justiça das quais as empresas faziam parte - como autoras ou rés. As grandes companhias estavam presentes em $53,4 \%$ delas, o gasto de manutenção desses processos foi de $1.67 \%$ do faturamento, o número médio de ações por empresas foi de 186 . Já as médias empresas responderam por $23,8 \%$ dos processos e comprometeram $1.89 \%$ de seu faturamento; e as pequenas participaram de $22,80 \%$ das ações e gastaram o equivalente a $1,43 \%$ do que ganharam em 2012. As custas judiciais e extrajudiciais representaram $\mathrm{R} \$ 23$ bilhões; os gastos com advogados, chegou a quase $\mathrm{R} \$ 17$ bilhões; perícias, $R \$ 2,1$ bilhões; viagens e hospedagens, $R \$ 529$ milhões; valores usados com pessoal e sistemas de controle, $\mathrm{R} \$ 2$ bilhões. O maior montante, porém, foi pago pelas empresas condenadas em processos finalizados em 2012. A conta com multas, encargos legais e indenizações (como danos morais) correspondeu a R\$ 65 bilhões naquele ano (BASTOS; CORRÊA; PASSANI, 2014, p. 29).
}

O autor destaca os autos custos das empresas privadas com as ações judiciais que 
além de comprometer as finanças, também é prejudicial para a imagem da empresa. Nesse sentido como forma de amenizar os custos, as grandes corporações passam a investir maciçamente em mecanismos de resolução extrajudicial de conflitos por tratar-se de formas mais eficientes para o alcance dos objetivos. Com as empresas públicas a situação não é diferente, ainda de acordo com os autores, neste mesmo estudo,

\begin{abstract}
Os números mostram que dos 92 milhões de processos, $51 \%$ são dos governos, entre federal, estaduais e municipais, $38 \%$ do sistema financeiro e $6 \%$ das telecomunicações. Esta soma dá 95\%. Ora, são grandes corporações que estão em juízo. Se é assim, é possível que nós pensemos em uma estratégia nacional, que tenha por base, por meta principal, a mediação, para que nós possamos resolver os conflitos e evitar cada vez mais a sua judicialização (BASTOS; CORRÊA; PASSANI, 2014, p. 30).
\end{abstract}

Ao mencionar esses números, os autores evidenciam os altos índices que as empresas privadas despendem para custear os processos judiciais, levando em consideração os altos valores envolvendo as custas processuais, perícias e possíveis penhoras. Com os órgãos públicos a questão não é diferente. Segundo Conselho Nacional de Justiça (CNJ), em Relatório publicado no ano de 2011, sobre "A Execução Fiscal no Brasil e o Impacto no Judiciário", ficou demonstrado os números dos processos em tramitação pela justiça brasileira. O estudo foi fornecido por duas entidades, a Universidade Federal do Rio Grande do Sul (UFRGS) que examinou as inter-relações entre o processo administrativo e o judicial na esfera fiscal.

O outro estudo foi realizado pelo Instituto de Pesquisa Econômica Aplicada (IPEA) que abrangeu o desafio de estimar o custo e o tempo médio para o Judiciário dos processos de execução fiscal na Justiça Federal que respondem por $34,6 \%$ da carga processual desse ramo do Judiciário. Os dois estudos oferecem insumos valiosos para retratar o panorama da execução fiscal no Brasil. As pesquisas em última fase que envolveu a tabulação e concreção da análise de dados, foi apresentado o relatório final em dois volumes no qual o primeiro tratou da pesquisa jus-sociológica de Campo e o segundo a pesquisa jus-doutrinária comparada que revelou o que segue:

O Poder Judiciário Nacional não está aparelhado para lidar com as demandas tributárias. A falta de garantias inerentes à magistratura por parte dos membros da administração tributária encarregados do julgamento de lides tributárias gera desconfiança na isenção da Administração Pública e aumenta a demanda judicial. Não há diferença essencial entre as funções administrativa e a judicial, podendo a própria coisa julgada material ser conferida a atos administrativos, denotando uma forma arcaica de divisão de poderes, da qual a administração ainda é dependente. Quando iniciada a execução do título executivo extrajudicial, esta pode ser embargada, permitindo ao contribuinte repetir no judiciário toda a discussão havida na esfera administrativa quanto a questões de fato e de direito. Não há regra que determine o aproveitamento de elementos do julgamento administrativo na via judicial, fato que pode levar à repetição do trabalho, gerando duplicação de esforços. A arrecadação pelo atual sistema de execução fiscal é uma demonstração cabal de sua ineficiência e uma das principais causas da aposta crescente dos contribuintes na vantagem de não pagar os tributos no prazo, dado que o Estoque da Dívida Ativa da União representa cerca de metade do valor de toda a Dívida Pública da União. RELATÓIRO CNJ publicado no ano de 2011, sobre "A Execução Fiscal no Brasil e o Impacto no Judiciário".

O relatório teve como principal objetivo, motivar o debate sobre possíveis novos rumos para a execução fiscal no Brasil, de maneira a ao aprimorar a prestação jurisdicional não somente em matéria relativa à execução fiscal, mas do sistema judicial de forma geral. 
A pesquisa comprovou um aumento considerável de demanda na esfera administrativa, visto que o Conselho Administrativo de Recursos Fiscais (CARF) passou de 30.000 processos em 2008 para 70.000 em 2010 (BRASIL, 2011). O estudo relata ainda que a maior parte dos julgados das Delegacias da Receita Federal do Brasil de Julgamento (DRJs) é ajuizada improcedente e, por via de regra, a decisão é confirmada pelo Conselho Administrativo de Recursos Fiscais (CARF). Ainda assim, a maior parte desses julgados acaba desmoronando no Judiciário.

Segundo o relatório Justiça em Números do Conselho Nacional de Justiça (CNJ), publicado em 2017, ano base de 2016 as despesas e receitas totais ${ }^{1}$, do Poder Judiciário somaram $\mathrm{R} \$ 84,8$ bilhões o que representou crescimento de $0,4 \%$ em relação ao último ano e uma média de 3,9\% ao ano desde de 2011. As despesas totais do Poder Judiciário correspondem a $1,4 \%$ do produto interno bruto (PIB) nacional, ou a $2,5 \%$ dos gastos totais da União, dos estados, do Distrito Federal e dos Municípios.

Em 2016, o custo pelo serviço de Justiça foi de R $\$ 411,73$ por habitante. A despesa da Justiça Estadual, segmento mais representativo, que abarca $79 \%$ dos processos em tramitação, responde por aproximadamente $57 \%$ da despesa total do Poder Judiciário. O relatório Justiça em Números aponta ainda o Panorama Global ${ }^{2}$ que o Poder Judiciário, finalizou o ano de 2016 com 79,7 milhões de processos em tramitação, aguardando alguma solução definitiva. Desses, 13,1 milhões, ou seja, 16,4\%, estavam suspensos ou sobrestados ou em arquivo provisório aguardando alguma situação jurídica futura.

Os estudos revelam que durante o ano de 2016, ingressaram 29,4 milhões de processos no Poder Judiciário. Um crescimento em relação ao ano anterior na ordem de 5,6\% e $2,7 \%$ respectivamente. Tal incremento da produtividade dos magistrados e servidores chegou a 30,8 milhões de casos julgados em 2016. Chama atenção a diferença entre o volume de processos pendentes e o volume que ingressa a cada ano. O Relatório ao analisar o Poder Judiciário como um todo, dispôs que, mesmo que o Poder Judiciário fosse paralisado sem ingresso de novas demandas e mantida a produtividade dos magistrados e dos servidores, seriam necessários aproximadamente 2 anos e 8 meses de trabalho para zerar as demandas.

Os gargalos da execução ${ }^{3}$, a cada ano a publicação do Relatório Justiça em Números destaca o impacto negativo gerado pela fase de execução nos dados de litigiosidade do Poder Judiciário brasileiro, que acumula alto volume de processos e alta taxa de congestionamento. Esse volume dificulta a efetivação da tutela jurisdicional. De acordo com o Relatório, a maior parte dos processos de execução é composta pelas execuções fiscais, que representa $75 \%$ do estoque. Esses processos são os principais responsáveis pela alta taxa de congestionamento do Poder Judiciário, tendo em vista que representam aproximadamente $38 \%$ do total de casos pendentes, apresentando congestionamento de $91 \%$ em 2016, a maior taxa entre os tipos de processos constantes desse Relatório.

Conforme o Relatório, no quadro geral das execuções fiscais ${ }^{4}$, o maior problema é a fiscal. De acordo com o Relatório, o executivo fiscal chega a juízo depois que as tentativas de recuperação do crédito tributário se frustraram a via administrativa, provocando 
sua inscrição na dívida ativa. Dessa forma, o processo judicial acaba por repetir etapas e providencias de localização do devedor ou patrimônio capaz de satisfazer o crédito tributário já adotados, sem sucesso, pela administração fazendária ou pelo conselho de fiscalização profissional.

Acabam chegando ao Judiciário títulos cujas as dívidas já são antigas, e por consequência, mais difíceis de serem recuperadas. Essa classe de processo apresenta alta taxa de congestionamento. O relatório aponta que 91\%, ou seja, de cada 100 (cem) processos de execução fiscal que tramitaram no ano de 2016, apenas 9 (nove) foram baixados. A maior taxa de congestionamento de execução fiscal está na Justiça Federal. O Relatório dispõe que a conciliação abrange um percentual significativo de sentenças e decisões resolvidas por homologação de acordo em relação ao total de decisões terminativas proferidas. Em 2016, 11,9\% das sentenças e decisões proferidas no Poder Judiciário, foram homologatórias de acordo.

A tendência é o aumento das homologatórias de acordo. A conciliação é uma prática adotada pelo CNJ desde de 2006 que promove as Semanas Nacionais pela Conciliação, momento em que os tribunais são incentivados a juntar as partes e promover acordos pré e endo processual.

\section{CONSIDERAÇÕES FINAIS}

Com base nos entendimentos acima expostos, é possível vislumbrar que pesquisar sobre a matéria tributária possui extrema relevância no funcionamento do Estado como um todo, além disso, seus princípios se fazem fundamentais para o correto e devido funcionamento da máquina estatal na função de arrecadar tributos. A diversidade de modalidades de transação tributária, a serviço do interesse público, representa um importante passo para o desenvolvimento da sociedade brasileira. Nessa ordem, o Projeto de Lei $n^{\circ}$. 5.082/2009, dispõe sobre a mediação entre particulares como meio alternativo de solução de controvérsias e sobre a composição de conflitos no âmbito da Administração Pública.

A partir da Constituição de 1824, denominada Constituição do Império a regulamentação do Direito Tributário começa a dar seus primeiros passos, mas somente com a Emenda Constitucional no 18 de 1965, ocorreu a regulamentação e seguidamente em 1966 o Direito Tributário veio alcançar a situação de ramo jurídico autônomo na ordem jurídica do Brasil com a publicação do CTN e posteriormente com a Constituição Federal de 05.10.1988, alcançou definitivamente o reconhecimento do Direito Tributário como o ramo autônomo pertencente ao direito público.

O Estado Moderno passa então a ser regulado por lei, com a intervenção direta do Estado na vida dos cidadãos, alcançado a forma de Estado Social de Direito e exercendo o denominado poder de tributar. Mas ao exercer o poder de tributar precisa respeitar limites ao poder fiscal do Estado. Mas a supremacia do Estado é ilimitada, havendo a obrigatoriedade de reverenciar as normas constitucionais tendo como princípios basilares a legalidade e a indisponibilidade do Interesse público sobre o interesse privado. Para melhores esclarecimentos, a indisponibilidade do interesse público representa o somatório dos interesses individuais, ou seja, representa a vontade da maioria. Segundo esse princípio a Administração 
Pública não pode dispor desse interesse geral, da coletividade, nem renunciar a poderes que a lei lhe deu para tal tutela, mesmo porque ela não é titular do interesse público, cujo titular é o Estado.

Nesse entendimento, diante de toda a trajetória pela qual passou o Direito Tributário, o segundo capitulo da pesquisa apresentou as principais formas de resolução extrajudicial de conflitos, dando especial atenção à autocomposição, ocorre, que à Administração Pública não cabe a renúncia (dispor) do interesse público, para solucionar um interesse individual do contribuinte, salvo quando autorizada pelo direito.

Nesse sentido os poderes da Administração têm caráter de poder-dever, os quais ela não pode deixar de exercer sob pena de responsabilização, pois o poder de tributar do Estado não é absoluto. O ideal seria que tais interesses fossem coincidentes, pois do contrário, prevalece o interesse primário e a interferência do Poder Judiciário.

Consoante ao exposto percebe-se as mudanças constantes ocorridas na sociedade como um todo não surtiu efeitos suficientes para pôr fim aos conflitos entre os indivíduos de forma a transformar significativamente o modo de vida dos brasileiros. Desse modo, os conflitos são levados ao Judiciário por meio de ações coletivas ou individuais causando o aumento de ações e consequentemente uma sobrecarga de processos no Poder Judiciário brasileiro, afetando drasticamente a economia do país, representando custos elevados para o Estado e sobrepeso à sociedade como um todo.

Ao finalizar o estudo abordou-se um aumento considerável de demanda na esfera administrativa, visto que o Conselho Administrativo de Recursos Fiscais (CARF) passou de 30.000 processos em 2008 para 70.000 em 2010. E revela que a maior parte dos julgados das Delegacias da Receita Federal do Brasil (DRJs), sãos ajuizadas improcedentes, desaguando no judiciário.

Segundo o relatório Justiça em Números do Conselho Nacional de Justiça (CNJ), publicado em 2017, as despesas e receitas totais, do Poder Judiciário somaram $\mathrm{R} \$ 84,8$ bilhões. O Relatório aponta que o Poder Judiciário, finalizou o ano de 2016 com 79,7 milhões de processos em tramitação, aguardando alguma solução definitiva. O estudo revela que durante o ano de 2016, ingressaram 29,4 milhões de processos no Poder Judiciário e acrescenta, "se o Poder Judiciário fosse paralisado sem ingresso de novas demandas e mantida a produtividade dos magistrados e dos servidores, seriam necessários aproximadamente 2 anos e 8 meses de trabalho para zerar as demandas".

Resta evidente que o volume de processos, dificulta a efetivação da tutela jurisdicional. Relatório de 2016 aponta que a maior parte dos processos de execução é composta pelas execuções fiscais, que representa $75 \%$ do estoque. Esses processos são os principais responsáveis pela alta taxa de congestionamento do Poder Judiciário, tendo em vista que representam aproximadamente $38 \%$ do total de casos pendentes, apresentando congestionamento de $91 \%$ em 2016. E ainda revela que o executivo fiscal chega a juízo depois que as tentativas de recuperação do crédito tributário se frustraram a via administrativa, provocando sua inscrição na dívida ativa. Dessa forma, o processo judicial acaba por repetir etapas e providencias de localização do devedor ou patrimônio capaz de satisfazer o crédito tributá- 
rio já adotados, sem sucesso, pela administração fazendária. Os títulos da dívida pública quando chegam ao Judiciário já são antigos, e por consequência, mais difíceis de serem recuperadas. Essa classe de processo apresenta alta taxa de congestionamento.

O relatório destaca que $91 \%$, ou seja, de cada 100 (cem) processos de execução fiscal que tramitaram no ano de 2016, apenas 9 (nove) foram baixados. A maior taxa de congestionamento de execução fiscal está na Justiça Federal. Consoante a todo o exposto, o que se verifica é que a sentença de mérito finaliza a lide levada ao judiciário, mas na maioria das vezes o conflito permanece por não haver a participação das partes na tomada da decisão final.

O estudo nos leva a refletir que o Estado brasileiro precisa evoluir com a sociedade ao que tange a cobrança do crédito tributário. De forma tal que precisa adotar métodos alternativos de solução de conflitos eficazes e capazes de solucionar litígios em matéria tributária.

Para fins de entendimento e analisando os métodos de solução de conflitos apresentados no decorrer da pesquisa, nota-se, que o Estado brasileiro dispõe de uma infinidade de previsões legais capazes de solucionar conflitos e aplicar a cultura de pacificação social nos diferentes ramos da Justiça Nacional. Porém em se tratando de matéria tributária, ainda não dispõe de métodos eficazes, capazes de solucionar litígios que envolvem a Fazenda Pública. Visto que não há previsão legal estabelecendo meios alternativos de solução de conflitos de forma consensual em face princípio da indisponibilidade do interesse público sobre o interesse privado.

Os resultados obtidos com essa pesquisa precisam urgentemente motivar o debate sobre possíveis novos rumos para a execução fiscal no Brasil levando-se em consideração que o Estado brasileiro encontra-se caoticamente submerso em processos judiciais necessitando urgentemente adotar meios alternativo para solucionar conflitos tributários de forma que conflito em uma demanda possa tratado de maneira benéfica à sociedade, para tal, dependerá da importância que lhe será dada e a forma como será conduzido.

Em resposta ao problema da pesquisa, constata-se que os métodos alternativos de resolução de conflitos podem ser aplicados em matéria tributária sem que isso comprometa ou ponha em risco a indisponibilidade e a supremacia do interesse público. Nesse sentido, a pesquisa propõe a utilização da transação como ferramenta capaz de dirimir conflitos em matéria tributária, aplicando-se o que estabelece o art. 156, inciso III e art. 171, caput do CTN, como forma de reduzir a litigiosidade no âmbito tributário e consequentemente a redução dos custos com estes processos minimizando os prazos para recebimento dos créditos e potencializar o grau de eficiência e eficácia da Administração Tributária em juízo de oportunidade e conveniência, restando claro que a transação só poderá ocorrer em havendo previsão legal. A falta de autonomia da Fazenda Pública em extinguir o crédito tributário, em condições adversas como essa, expõe à precariedade do sistema de cobrança, onerando demasiadamente os cofres públicos, além de ser morosidade e pouca eficácia no que concerne à constrição do devedor que não possui patrimônio para saldar a dívida.

A pesquisa sugere um debate no aprimoramento da prestação jurisdicional em matéria relativa à execução fiscal e propõe um "novo" modelo arrecadatório, incorporando a 
hipótese de que dispor do crédito público em determinadas condições para tentar solucionar o conflito também é uma forma de atender ao interesse público.

\section{NOTAS}

1. http://www.cnj.jus.br/programas-e-acoes/pj-justica-em-numeros .p.53

2. http://www.cnj.jus.br/programas-e-acoes/pj-justica-em-numeros. p.67

3. http://www.cnj.jus.br/programas-e-acoes/pj-justica-em-numeros. p. 109

4. http://www.cnj.jus.br/programas-e-acoes/pj-justica-em-numeros. p. 113

\section{REFERÊNCIAS}

ALEXANDRE, Ricardo. Direito Tributário Esquematizado. 7. ed. rev. e atual. Rio de Janeiro: Forense; São Paulo: Método, 2013.

BALTHAZAR, Ubaldo César. História do Tributo no Brasil. Florianópolis: Fundação Boiteux, 2005.

BASTOS, Simone de Almeida Ribeiro; CORREAA, Marcelo Girade; PASSANI, Andrezza Gaglionone; Panorama da Autocomposição no Brasil. In: OLIVEIRA, Igor Lima Goettenauer de (Org.). Resolução de Conflitos para Representantes de Empresas. 1. ed. Brasília, DF: Fundação Universidade de Brasília/ UFB, 2014, p. 01-159.

BRASIL. Câmara Federal. Projeto de Lei $n^{\circ}$ 5.082/2009. Disponível em: http://www.camara.gov.br/ proposicoesWeb/fichadetramitacao?idProposicao=431269. Acesso em: 01 mai. 2018.

BRASIL. Código de Processo Civil. Lei 13.105/2015. Diário Oficial da União, Brasília, DF, 16 mar. 2015. Disponível em: http://www.planalto.gov.br/ccivil_03/_ato2015-2018/2015/lei//13105.htm. Acesso em: 11 jun. 2018.

BRASIL. Código Penal. Decreto-Lei 2.848/1940. Diário Oficial da União, Brasília, DF, 31 dez. 1940. Disponível em: http://www.planalto.gov.br/ccivil 03/decreto-lei/Del2848compilado.htm. Acesso em: 07 jun. 2018.

BRASIL. Código Tributário Nacional. Lei n 5.172/1966. Diário Oficial da União, Brasília, DF, 27 out. 1966. Disponível em: http://www.planalto.gov.br/ccivil_03/Leis/L5172.htm. Acesso em: 13 jun. 2018.

BRASIL. Conselho Nacional de Justiça. A Execução Fiscal no Brasil e o Impacto no Judiciário. 2011. Disponível em: http://www.cnj.jus.br/files/conteudo/ arquivo/2016/03/2d53f36cdc1e27513af9868de9d072dd.pdf. Acesso em: 01 mai. 2018.

BRASIL. Conselho Nacional de Justiça. Resolução n 125, de 29 de novembro de 2010. Disponível em: http://www.cni.jus.br/atos-normativos?documento=156. Acesso em: 08 mai. 2017.

BRASIL. Constituição Federal. Diário Oficial da União, Brasília, DF, 5 out. 1988. Disponível em: http:// www.planalto.gov.br/ccivil 03/Constituicao/Constituicao.htm. Acesso em: 02 jun. 2018.

BRASIL. Constituição Política do Império do Brazil. 1824. Disponível em: http://www.planalto.gov.br/ 
ccivil 03/constituicao/constituicao24.htm. Acesso em: 07 jun. 2018.

BRASIL. Lei n 6.830/1980. Diário Oficial da União, Brasília, DF, 24 set. 1980. Disponível em: http://www. planalto.gov.br/ccivil 03/leis/L6830.htm. Acesso em: 13 jun. 2018.

BRASIL. Lei n 8.429/1992. Diário Oficial da União, Brasília, DF, 03 jun. 1992. Disponível em: http://www. planalto.gov.br/ccivil 03/Leis/l8429.htm. Acesso em: 09 jun. 2018.

BRASIL. Lei n 9.099/1995. Diário Oficial da União, Brasília, DF, 27 set. 1995. Disponível em: http://www. planalto.gov.br/ccivil_03/Leis/L9099.htm. Acesso em: 05 jun. 2018.

BRASIL. Superior Tribunal de Justiça. Recurso Especial $n^{\circ}$. 514351 PR 2003/0023163-7. Primeira Turma. Ministro Luiz Fux. Julgado em: 20 mar. 2003. Disponível em: https://stj.jusbrasil.com.br/ jurisprudencia/210316/recurso-especial-resp-514351-pr-2003-0023163-7\#!,06-05-1711:27. Acesso em: 09 jun. 2018.

COSTA, Elisson Pereira da, Direito administrativo II. 32. ed. São Paulo: Saraiva, 2012.

GIACOMOLLI, Nereu José. Juizados Especiais Criminais: Lei 9.099/95: abordagem crítica. 3. ed. ver. atual. Porto Alegre: Livraria do Advogado Editora, 2009.

MARTINS, Sérgio Pinto. Manual de Direito Tributário. 4. ed. São Paulo: Atlas, 2005.

MEIRELLES, Hely Lopes; ALEIXO, Délcio Balestero; FILHO, José Emmanuel Burle. Direito Administrativo Brasileiro. 41. ed. atual. São Paulo: Malheiros 2015.

MACHADO, Hugo de Brito. Curso de Direito Tributário. 36. ed. São Paulo: Malheiros, 2015.

MELLO, Celso Antônio Bandeira de. Curso de Direito Administrativo. 31. ed. rev. atual., São Paulo: Malheiros, 2014.

MOORE, Christopher. O processo de mediação. Estratégias práticas para resolução de conflitos. Porto Alegre: Ed. Artes Médicas, 1998.

NOGUEIRA, Ruy Barbosa. Curso de Direito Tributário. 14. ed. atual. São Paulo: Saraiva, 1995.

SABBAG, Eduardo de Moraes. Direito Tributário Essencial. 3. ed. rev. atual. e amp. Rio de Janeiro: Forense; São Paulo: Método, 2015.

SANTOS, Maria Januária Vilela. História Geral: $1^{\circ}$ grau. 2. ed. São Paulo: Ática, 1978.

VASCONCELOS, Carlos Eduardo de. Mediação de Conflitos e Práticas Restaurativas. 3.ed.rev. e atual. e amp. São Paulo: Método, 2014.

Recebido em: 20/11/2018

Aceito em: 04/12/2018 